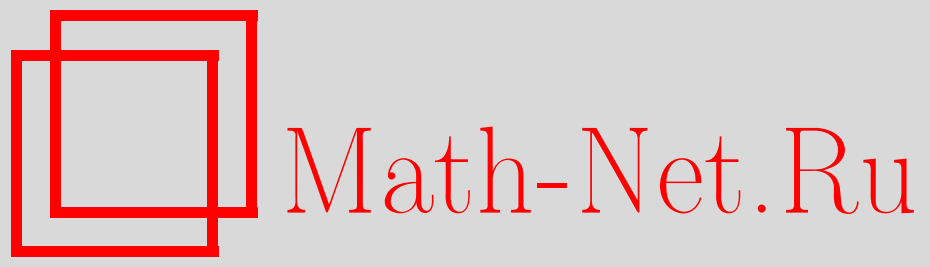

С. Кузнецов, Еще раз о полуправильных многогранниках, Квант, 2019, номер 3, 29-31

DOI: https://doi.org/10.4213/kvant20190304

Использование Общероссийского математического портала Math-Net.Ru подразумевает, что вы прочитали и согласны с пользовательским соглашением http://www.mathnet.ru/rus/agreement

Параметры загрузки:

IP: 54.80 .97 .219

26 апреля 2023 г., 14:15:15

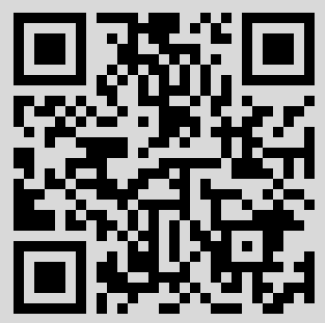




\section{Еще раз о полуправильных многогранниках}

\section{С.КУЗНЕЦОВ}

«КАЛЕЙДОСКОПЕ «КВАНТА» В №11 ЗА

2018 год мы рассказывали о полуправильных многогранниках, т.е. выпуклых многогранниках, грани которых суть правильные многоугольники и все вершины устроены одинаковым образом. Была приведена полная классификация таких многогранников: две бесконечные серии - призмы и антипризмы, пять правильных многогранников (платоновых тел: икосаэдр, куб, октаэдр, додекаэдр и икосаэдр) и еще 14 многогранников, традиционно называемых архимедовыми. Полуправильный многогранник определяется типом вершины: информацией, какие многоугольники сходятся к ней и в каком порядке. Например, $(3,4,4)$, т.е. «треугольник-квадрат-квадрат» - это треугольная призма. При этом одному из типов вершин, а именно $(3,4,4,4)$, отвечают сразу два многогранника: ромбокубооктаэдр и псевдоромбокубооктаэдр.

Псевдоромбокубооктаэдр стоит среди полуправильных многогранников особняком и дело не только в том, что его открыли в XX веке, в то время как остальные были извес-

DOI: https://doi.org/10.4213/kvant20190304 тны еще древним грекам. В отличие от других полуправильных, этот многогранник не обладает глобальной симметрией, или свойством транзитивности: хоть любые две его вершины и устроены одинаковым образом, не всегда их можно совместить движением, переводящим многогранник в себя. Из-за этого псевдоромбокубооктаэдр не всегда относят к архимедовым телам, и тогда последних остается 13.

Наш постоянный читатель О.Лазутченко задал следующий интересный вопрос. Псевдоромбокубооктаэдр получается из обычно-
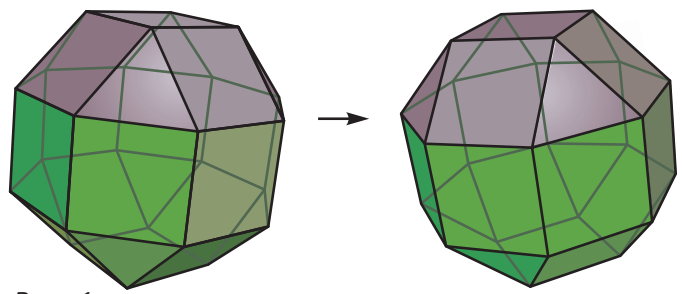

Pис. 1

го ромбокубооктаэдра поворотом «шапочки» (рис.1). Эта «шапочка» называется $n$ скатным куполом, где $n$ - число сторон ее верхней грани. А что будет, если повернуть «шапочку» у другого полуправильного многогранника - ромбоикосододекаэдра (рис.2)? Результат немного разочаровывает: получившийся многогранник еще дальше от «правильности», чем полуправильные. У него по-прежнему к каждой вершине сходятся четыре правильных многоугольника - треугольник, два квадрата и пятиугольник, но в разном порядке. У некоторых вершин порядок остался $(3,4,5,4)$, а у других стал $(3,4,4,5)$. Однако почему бы не рассмотреть полуправильные многогранники в слабом cмысле: потребовать, чтобы к каждой вер-

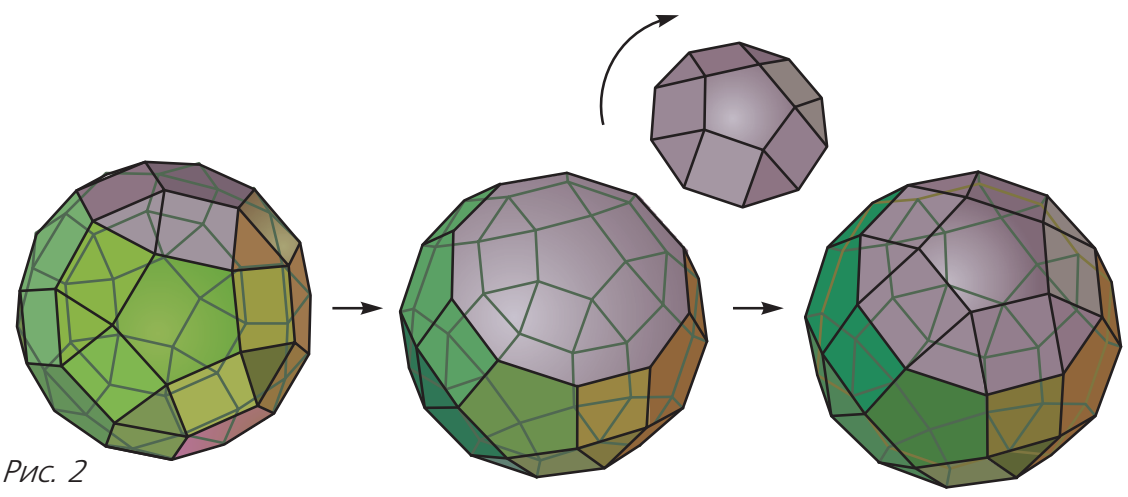


шине сходился одинаковый набор многоугольников, но в произвольном порядке?

Давайте попробуем перечислить все многогранники, полуправильные в слабом смысле. Воодушевляет на такое исследование следующий более общий факт. Отбросим любые условия на вершины и потребуем только, чтобы у многогранника все грани были правильными многоугольниками - все равно, кроме призм и антипризм, получится конечное число разных многогранников! Такие многогранники называются правильногранными. Полная классификация правильногранных многогранников приведена в статье В.А.Залгаллера «Выпуклые многогранники с правильными гранями» (Записки научных семинаров ЛОМИ, №2, 1967, c.5-221). Статья Залгаллера доступна по адресу http: / / mi.mathnet.ru / znsl1408- несмотря на ее большой объем и сложность, мы очень советуем читателю ознакомиться с ней.

Семейство правильногранных многогранников включает в себя пять платоновых тел, 13 архимедовых плюс псевдоромбокубооктаэдр, бесконечные серии призм и антипризм, а также еще 91 многогранник. Эти последние многогранники называются джонсоновыми телами по имени автора статьи, в которой они впервые все были перечислены: N.W.Johnson. Convex polyhedra with regular faces (Canadian Journal of Mathematics, vol.18, 1966, p.169-200, https://doi.org/ 10.4153/CJM-1966-021-8). Псевдоромбокубооктаэдр также относится к джонсоновым телам, если его не причислять к архимедовым; тогда джонсоновых тел становится 92. В своей работе Н.Джонсон приводит перечень всех джонсоновых тел, но не доказывает, что других не бывает (это сделал в упомянутой выше статье В.А.Залгаллер).

Нас интересуют полуправильные в слабом смысле многогранники, не являющиеся таковыми в сильном смысле. Ясно, что все они суть джонсоновы тела. Значит, нам достаточно перебрать все джонсоновы тела и отобрать среди них те, у которых в каждой вершине сходятся одни и те же многогранники. Особенно удобно делать это по статье Джонсона, где для каждого многогранника указаны типы его вершин, т.е. какие многоугольники и в каком количестве сходятся в каждую вершину.
Наш перебор дает 6 новых правильногранных многогранников, у которых в каждой вершине сходятся те же многоугольники, но в разном порядке. Интересно, что все они получаются из архимедовых многогранников с помощью операции «поворота шапочки», описанной в начале статьи. Перечислим эти шесть многогранников.

Во-первых, поворотом купола у ромбоикосододекаэдра, как предложил нам О.Лазутченко, можно получить целых четыре многогранника (у Джонсона они имеют номера 7275). Многогранников получилось несколько, потому что можно повернуть не один, а два или даже три купола. Надобно только следить, чтобы эти купола не имели общих граней: при повороте купол «ломает» все смежные с ним купола. Если повернуть один купол, то получится скрученный ромбоикосододекаэдр (рис.3). Два купола можно повернуть двумя способами - либо один напротив другого, и тогда получится дважды противоположно скрученный ромбоикосододекаэдр (рис.4); либо два непротиволежащих, что дает дважды косо скрученный ромбоикосододекаэдр (рис.5). Наконец, три непересекающихся купола можно выбрать только одним способом; повернув их, получим трижды скрученный ромбоикосододе$к а э д p$ (рис.6). По Залгаллеру, скрученные версии ромбоикосододекаэдра обозначаются так: $\bar{M}_{6}+\mathrm{M}_{14}+\mathrm{M}_{6}$ или $\overline{\mathrm{M}}_{6}+\mathrm{M}_{13}+2 \mathrm{M}_{6}$; $\bar{M}_{6}+M_{14}+\bar{M}_{6} ; 2 \bar{M}_{6}+M_{13}+M_{6} ; 3 \bar{M}_{6}+M_{13}$.

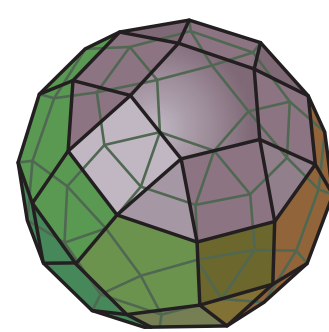

Pис. 3

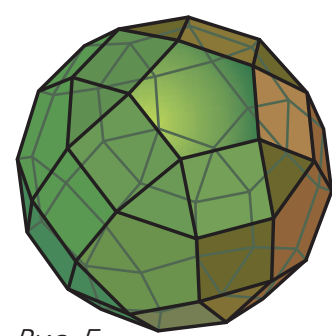

Pис. 5

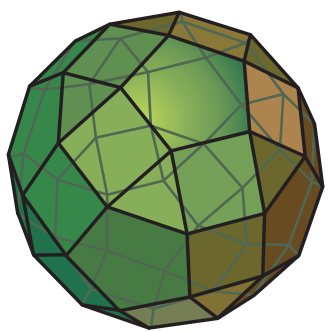

Pис. 4

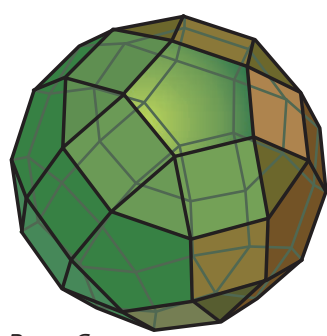


(Через $\mathrm{M}_{i}$ Залгаллер обозначает простые правильногранные многогранники, которые нельзя составить из нескольких правильногранных многогранников; остальные правильногранные многогранники получаются в виде «сумм» простых, при этом черта означает перекручивание. Видно, что $\mathrm{M}_{6}$ - это как раз и есть «шапочка», пятискатный купол.)

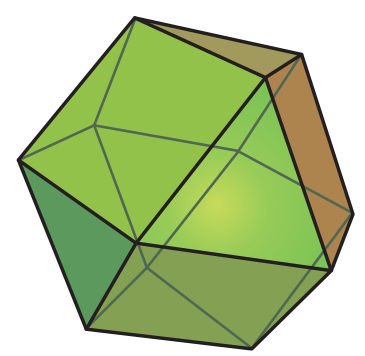

Во-вторых, заметим, что кубооктаэдр (рис.7) складывается из двух трехскатных куполов, причем повернутых друг относительно друга так, что треугольные грани верхнего купола смежны с Pис. 7 квадратными гранями нижнего и наоборот. Это объясняет другое название кубооктаэдра-трехскатный повернутый бикупол (или трехскатный гиробикупол: приставка «гиро», греческого происхождения, означа-

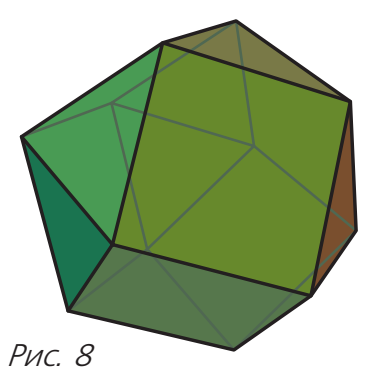
ет «повернутый»). Если развернуть один из куполов так, что квадраты будут смежны с квадратами, а треугольники с треугольниками, получится еще одно полуправильное в слабом смысле тело трехскатный прямой бикупол (рис. 8; №27

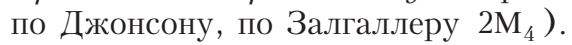

В-третьих, еще один многогранник можно получить поворотом из икосододекаэдра

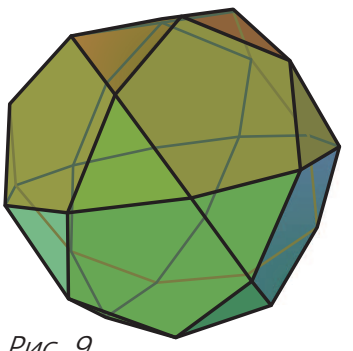

(рис.9), повернув одну его половину. В отличие от предыдущих случаев, здесь поворачивается не купол, а более сложная конструкция, называемая ротондой (рис.10). Получается полуправильный в слабом смысле многогранник, называемый пятискатной прямой биротондой (рис.11, №34 по Джонсону, по Залгаллеру

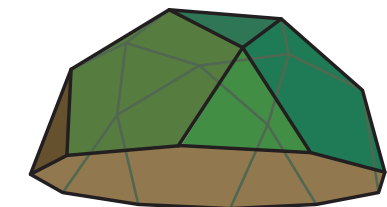

Рис. 10

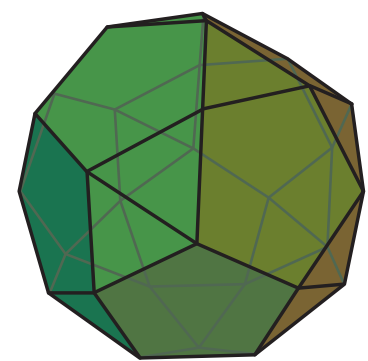

Pис. 11

$2 \mathrm{M}_{9}$ ). Сам икосододекаэдр можно назвать пятискатной гиробиротондой.

Наконец, не считая псевдоромбокубооктаэдр полноправным архимедовым телом, Джонсон и Залгаллер также приводят его в числе джонсоновых (№37 у Джонсона, $\mathrm{M}_{5}+\Pi_{8}+\overline{\mathrm{M}}_{5}$ у Залгаллера) под именем удлиненный четырехскатный повернутый бикупол («удлиненный» - потому что в середине между двумя куполами вставлена призма).

Таким образом, мы получили следующую классификацию правильногранных многогранников по мере их «удаления от правильности»:

- все грани и все вершины одинаковые 5 платоновых тел (правильных многогранников);

- все вершины одинаковы и совмещаются симметрией многогранника - добавляется еще 13 архимедовых тел и две бесконечные серии призм и антипризм;

- все вершины одинаковы, но не обязательно совмещаются симметрией - добавляется еще псевдоромбокубооктаэдр;

• в каждой вершине сходится тот же набор многоугольников, но не обязательно в том же порядке - добавляются еще 6 многогранников, полученных из полуправильных посредством перекручивания;

• нет условий на вершины - добавляются оставшиеся 85 джонсоновых тел.

Всего правильногранных многогранников, не считая призм и антипризм, получается $5+13+1+6+85=110$ видов. 